\title{
Overview and Value Analysis of Bianlong
}

\author{
Jikang Deng ${ }^{1}$ Xianqiong Ding ${ }^{1, *}$ Feng $\mathrm{Ao}^{2}$ Xiaojin $\mathrm{Su}^{3}$
}

\author{
${ }^{1}$ Physical Education College, Yunnan Normal University, Kunming, Yunnan 650500, China \\ ${ }^{2}$ Sports Association of the Elderly in Gao'an City, Jiangxi Province, Gaoan, Jiangxi 330800, China \\ ${ }^{3}$ Education College, Yunnan Normal University, Kunming, Yunnan 650500, China \\ *Corresponding author.
}

\begin{abstract}
This study uses the methods of expert interview, questionnaire survey, literature and other research methods to study the origin, the structure and the value of Bianlong. The research shows that the "back 8" movement of Bianlong has a special rehabilitation effect on shoulder periarthritis, cervical spondylosis and other joint diseases, and Bianlong has extremely high ornamental and commercial value. Some suggestions are put forward for the future development of Bianlong: formulating Bianlong courses and competition regulations, increasing the construction of Bianlong organization, and bringing Bianlong into the campus. It aims to lay the foundation for the development of Bianlong and academic research of Bianlong.
\end{abstract}

Keywords: Bianlong, value, future development

\section{INTRODUCTION}

Bianlong is an emerging traditional national sport that can be danced by all ages. In 2017, Bianlong was the official event of this competition in the First international Bianlong Tournament and the Sixth National whipping Tournament, which also marked the formal formation of Bianlong. In recent years, Bianlong has become one of the sports events in the community and square fitness and entertainment. At the same time, due to the rehabilitation effect of its sport form and movement characteristics, it has been favored by many middle-aged and elderly people. The development of Bianlong can be described as "the sudden formation and rapid development", but the definition, origin, value, structure and production specifications of Bianlong are all blank in academia. Therefore, the author, together with Ao Feng, the President of the Bianlong Association in the Sports association for Gao'an Senior Sports Association of Jiangxi Province, and Ding Xianqiong, Professor of Yunnan Normal University, conducted a basic research on the development of the Bianlong. In order to lay an academic foundation for the development and promotion of The Bianlong, the author conducted academic interviews with relevant experts and leaders such as Liu Jianzhou, President of China whip and peg-top Federation.

*Fund: 2020 provincial Postgraduate Tutor Team — Physical Education (00700205020502041).

\section{OVERVIEW OF BIANLONG}

\section{A. The origin of Bianlong}

Bianlong, also known as "coloured ribbon dragon" or "fitness colored dragon". It is a kind of dragon dance fitness project derived from whip art, which is between eurythmics and traditional dragon dance. It is composed of "shake, swing, cross, roll, pull, throw, plate, jump" and other basic actions and some skill actions. Generally, it is a kind of individual or collective dance with fitness function and appreciation value, which is performed under musical accompaniment on a spacious venue with a certain space height. The main artistic features are dancing vividly and expressing lively with many routines and stable rhythm. Dragon Dance modeling are in the process of swimming, that is, " the dragon is constantly deformed, and the dragon walks and dances." The rope leads the dragon, the Dragon follows the music, the Dragon flies the human dance, the dragon dance is vividly shaped, the movement transformation ingenious performance highlights the word "living", the movement is vigorous and light, the dance postures are varied, the complete set of movement manifests "the human and dragon unity".

The Bianlong was formally formed in the first international Bianlong Tounament and the Sixth National whip and peg-top Tournament, and now it has spread all over the country, with different development and scale in each region. Regarding the specific birthplace and formation of the Bianlong Movement, there is currently no unified conclusion. About the origin of the Bianlong, President Liu Jianzhou, of the China whip and peg-top Federation, said: "the Bianlong was performed by the 
whip and peg-top group (That is, the group that participates in the exercise of the whip and gyro) around 2015. The exerciser tied the ribbon to the tail of the whiplash for dancing, and then the exerciser added the ornament with a certain weight similar to the faucet in front of the ribbon. After continuous improvement by many exercisers, the current Bianlong exercise was born." About the origin of Bianlong, there is another folk saying that Bianlong is gradually evolved from the diabolo movement, because the structure and movement form of Bianlong are very similar to diabolo dragon.

\section{B. Structure and specification of Bianlong}

Bianlong consists of four parts: dragon head, dragon clothes, dragon tail and whip rope. The weight of the dragon head is $300-600 \mathrm{~g}$ (adjusted according to the length of the Dragon suit and the physical fitness of the dancer). The shape of the dragon head is $27 \mathrm{~cm}$ long, $14 \mathrm{~cm}$ wide and $26 \mathrm{~cm}$ high. The shape of the dragon head is "hornlike deer, head-like cattle, eyes-like shrimp, mouth-like donkey, and ears-like elephant" the mouth of the dragon is large, with a small bead in its mouth. Dragon clothes must have dragon fins and scales. The overall length of the dragon clothes does not include the dragon tail. It is $10 \mathrm{~m}$ for men and $8 \mathrm{~m}$ for women. The tail of a dragon is a trident or five prong floating, with a length of no less than $35 \mathrm{~cm}$. The length of whip rope is composed of whip rope and kite connector, with a length of $95-150 \mathrm{~cm}$ and a diameter of $9-15 \mathrm{~mm}$.

\section{The VAlue ANALYSIS OF BIANLONG}

\section{A. Fitness and Rehabilitation value of Bianlong}

People dance Bianlong relies on the coordination and cooperation of the whole body muscles, and the exercise intensity can be large or small. It is a typical aerobic and anaerobic combined body exercise. In the dance method, the rope leads the dragon, the Dragon follows the music; the rope flicks from side to side and rolls up and down; mainly consists of the Dragon fly, the Dragon roll, the dragon plate rotation and some technical actions. It can not only improve the cardiopulmonary function of the human body, but also enhance the physical quality of strength, endurance, flexibility, sensitivity and coordination. It is an excellent choice for fitness exercise.

Dancing Bianlong is a method of moving the feet from front to back and left to right. It can move the cervical vertebra by watching the movement of the faucet sometimes with both eyes. It can lubricating the joints, promoting the smooth flow of blood in the painful area, promoting the recovery of function, and achieving the purpose of rehabilitation. In France, there is a breast cancer patients Association, and hope that patients can practice dragon boating to curb the postoperative complications of lymphedema. Therefore, the Bianlong exercise has the same effect as practicing dragon boating against breast cancer.

The rehabilitation value of whipldragon is mainly aimed at diseases such as neck, shoulder, waist and leg pain, and joint pain in extremities. Through the combination of physical, mental exercises and body exercises, it directly hits the "acupoint BL 43" to relieve neck, shoulder, waist and leg pain. There is an idiom in China that goes "beyond cure". acupoint BL 43, It is a pair of important acupoints on the back of shoulder. Due to the concealment of acupoint BL 43, scraping can't penetrate and the hands can't be pressed. In addition to moxibustion treatment methods, there are also exercise, such as whiplash dragon exercise, which has a unique effect. There is also a saying in traditional Chinese medicine books that "exercise the acupoint BL 43 to remove the disease of one body". [1] [2]

Bianlong's dancing is a movement mode of " hands are dancing at the feet of the dragon, looking at the head of dragon from time to time". It forms a movement of "opening and closing acupoint BL 43" with the shoulder as the axis and the arm repeatedly rotating up and down left and right. Its function is to release the acupoint BL 43 activity, fully loosen the shoulder back, repeatedly stretching back and forth can make the chest expand, and keep exercising, not only can effectively solve the problem of shoulder and back pain, but also can effectively prevent heart and lung diseases. At the same time, the back can be opened and tightened like a fan through this exercise, which can refresh the whole body and reduce the shoulder back pain obviously.

In order to explore the rehabilitation value of Bianlong, 8 patients who participated in Bianlong exerciser were interviewed. At present, the main population participating in the Bianlong exercise is the middle-aged and elderly people, and the middle-aged and elderly people are high-risk groups of joints and other health diseases, so the eight subjects are all middle-aged and elderly people. Through in-depth conversation with 8 interviewees, the data in "Table I" is obtained. 
TABLE I. INVESTIGATION AND STATISTICS OF RESTORED TO HEALTH EFFECT OF BIANLONG

\begin{tabular}{|c|c|c|c|c|c|c|c|c|c|}
\hline No & Age & Sex & $\begin{array}{l}\text { How } \\
\text { long } \\
\text { (mo } \\
\text { nth) }\end{array}$ & $\begin{array}{l}\text { Exercise } \\
\text { frequency } \\
\text { and } \\
\text { intensity } \\
\text { (medium, } \\
\text { high, low) }\end{array}$ & $\begin{array}{l}\text { Durati } \\
\text { on of } \\
\text { one } \\
\text { exerci } \\
\text { se }\end{array}$ & Disease & $\begin{array}{c}\text { Description of illiness (age time } \\
\text { degree of illness) }\end{array}$ & $\begin{array}{l}\text { The best } \\
\text { action of } \\
\text { Bianiong }\end{array}$ & $\begin{array}{l}\text { Degre } \\
\text { e of } \\
\text { recov } \\
\text { ery }\end{array}$ \\
\hline 1 & 58 & Woman & 36 & Daily / high & 1h & $\begin{array}{l}\text { Cervical } \\
\text { spondylosis }\end{array}$ & $\begin{array}{l}\text { 5-year history, cervical } \\
\text { compression nerve, frequent } \\
\text { dizziness and headache }\end{array}$ & Back 8 & $100 \%$ \\
\hline 2 & 63 & Woman & 1.5 & $\begin{array}{l}\text { Daily / } \\
\text { medium }\end{array}$ & $15 \mathrm{~h}$ & $\begin{array}{l}\text { Cervical } \\
\text { spondylitis }\end{array}$ & $\begin{array}{l}6 \text { years of history, compression of } \\
\text { nerves, left hand pain unable to } \\
\text { lift, night hand numbness }\end{array}$ & $\begin{array}{l}\text { back } 8 \text {, } \\
\text { Front } 8\end{array}$ & $50 \%$ \\
\hline 3 & 64 & Man & 25 & Daily / high & $15 \mathrm{~h}$ & $\begin{array}{c}\text { Pain of } \\
\text { shoulder joint }\end{array}$ & $\begin{array}{c}4 \text { years of medical history, unable } \\
\text { to lift the hand completely }\end{array}$ & $\begin{array}{l}\text { Unable to } \\
\text { determine }\end{array}$ & 60\% \\
\hline 4 & 68 & Woman & 42 & Daily / low & 1h & $\begin{array}{l}\text { Lumbar disc } \\
\text { protrusion. } \\
\text { 5capulohume } \\
\qquad \text { ral } \\
\text { periarthritis }\end{array}$ & $\begin{array}{l}4 \text { years of history, low back pain } \\
\text { can not be bent down, and hand } \\
\text { pain activity is limited }\end{array}$ & Back 8 & 80 \% \\
\hline 5 & 68 & Man & 42 & Daily / low & In & $\begin{array}{l}\text { cervical } \\
\text { vertebra } \\
\text { hyperplasia }\end{array}$ & $\begin{array}{l}6 \text { years of history, unable to walk } \\
\text { with pain, numbness and } \\
\text { weakness of hands }\end{array}$ & Back 8 & $100 \%$ \\
\hline 6 & 53 & Man & 12 & Daily / high & $2 \mathrm{~h}$ & $\begin{array}{l}\text { scapulohume } \\
\text { ral } \\
\text { periarthritis }\end{array}$ & $\begin{array}{c}\text { hands cannot be lifted, } 3 \text { or } 4 \\
\text { years of iliness }\end{array}$ & $\begin{array}{r}\text { Front } 8 . \\
\text { Back } 8\end{array}$ & $80 \mathrm{~W}$ \\
\hline 7 & 56 & Woman & 18 & $\begin{array}{l}\text { Daily / } \\
\text { medium }\end{array}$ & $0.5 \mathrm{~h}$ & $\begin{array}{l}\text { scapulohume } \\
\qquad \text { ral } \\
\text { periarthritis }\end{array}$ & $\begin{array}{l}5 \text { years of history, Le pain, does } \\
\text { not affect other activities }\end{array}$ & Back 8 & $100 \%$ \\
\hline 8 & 70 & Man & 2 & $\begin{array}{l}\text { Daily/ } \\
\text { medium }\end{array}$ & Ith & Lung disease & $\begin{array}{l}6 \text { years history, haif a year in } \\
\text { hospital, dyspnea, insomnia }\end{array}$ & All actions & $70 \mathrm{~W}$ \\
\hline
\end{tabular}

According to the data in "Table I": 4 males and 4 females in the interviewee; The participation time was 3.5 years for the longest and 1.5 months for the shortest; Exercise frequency was daily; The duration of single exercise was about 1.5 hours; 4 people had shoulder disease, 3 people had cervical disease, 2 people had lumbar disease and 1 person had lung disease; The duration of disease was 3-6 years; The "back 8" movement of Bianlong had a special restored to health effect on shoulder periarthritis; The degree of rehabilitation was more than $50 \%$, of which 3 were $100 \%$. a. The Front 8and Back 8 here refer to regular actions in Bianlong.

The "back 8" is a basic action of whiplash dragon dance, that is, the Dragon flies left and right behind, with a horizontal " $\infty "$ trajectory. The "back 8 " can be completed by one arm alone or with two arms. To complete the single arm, it is necessary to lift the arm up, take the shoulder joint as the axis, draw a circle back to the other side of the head through the 60 degree angle of the body side, and then follow the inertial pendulum to start the next cycle. The completion of both arms is the same as that before the completion of single arm. The two arms need to be lifted up. First, one arm should take the shoulder joint as the axis, draw a circle backward through 
the 60 degree angle of the body side to the top of the head and change to the other arm, and complete a cycle with the same action. From the point of view of sports anatomy and biomechanics, the muscles on the front side of trunk coronal are all in the state of being pulled during the " back 8" movement, Such as: rectus abdominis, pectoralis major, pectoralis minor, etc. At the same time, the deltoid muscle is also in the state of traction and activity. The movement of these muscles and joints is contrary to the pathogenesis of most of the cervical spondylosis, scapulohumeral periarthritis and lumbar spondylosis that we are familiar with. This is the reason why the "later 8" movement of Bianlong achieves the magical health effect.

\section{B. The entertainment value of Bianlong}

When dancing the Bianlong, the performer holds the whip rope and shakes the dragon's clothing through the coordination of his whole body muscles, and then dances with the track of the dragon's head. Follow the rhythm of the music and use various postures of the human body to show the strength, speed, flexibility and coordination of the dragon, cool and soft to the audience[3]. The beauty starts from the rising, and the beauty is rolling. That is, the charm of Bianlong dance. What the audience perceives is the "Three Beauties", namely, the beauty of shape, body and emotion. Therefore, the action of Bianlong dance should have not only the speed of rhythm, but also the size of amplitude, and the dancing posture should be light and vigorous. Dragon flying and Phoenix dancing is the beauty of rolling like a cloud, and the charm of pure and quiet like a rainbow. In a word, both the performers and the audience can have a pleasant physical and mental effect.

\section{The commercial value of Bianlong}

Dragon-lion dance is an important symbol of Chinese traditional culture, which symbolizes good fortune, exorcism and evil spirits. Nowadays, when enterprises, public institutions, large shopping malls, hotels and other businesses opening or holding events, it is a normal practice to invite dragon-lion dancing teams to perform commercial performances. Therefore, professional dragon dance and lion dance performance teams and companies have also appeared on the market. Bianlong and lion dance have the same characteristics, the same cultural symbols and different forms of expression. When compared with dragon-lion dance, Bianlong dance has the following advantages: 1) each dragon or lion needs two or more dancers to dance at the same time, while Bianlong only needs one dancer, with less staff and low cost; 2)The weight of dragon and lion is large, which makes the performer's routine limited, while the Bianlong is light, the movement technology is complex and changeable, which can show more difficult, spectacular and majestic performances; 3) The cost of Bianlong is about 100 yuan, about one tenth of the cost of dragon and lion, so the cost is low. Of course, Bianlong has some disadvantages, such as weak cultural background and poor mass foundation.

\section{DEVELOPMENT STRATEGY OF BIANLONG}

\section{A. Making the course and competition rules of Bianlong}

For any sport to develop and grow, it is inseparable from a set of sound tutorials and competition rules [4]. At present, the main participants of Bianlong are mostly middle-aged and elderly people, whose skills learning speed is slow. Therefore, a simple and perfect teaching system can greatly help it and increase its enthusiasm for participation. At the same time, the establishment of teaching system is also a booster for teenagers to participate in the whiplash movement.

Since the successful holding of the first international Bianlong competition and the Sixth National whip and peg-top competition in 2017, Many large, medium and small-scale mass sports activities and art performances in China will invite Bianlong trainers to participate in competitions or performances. For example, in recent years, Jiangxi Gao'an whip, peg-top and Bianlong Association participated in the 2017 first international Bianlong competition and the Sixth National whip and peg-top competition, Gao'an 2018 National Fitness Day, 2018 Gao'an first blue and white goddess group selection competition, etc. Nowadays, many Bianlong exercisers in Gao'an of Jiangxi Province not only participate in Bianlong for physical training, but also for participating in competitions or performances, all eager to be on the stage and on the field. This has become a major driving force for them to adhere to the whipldragon. Therefore, we should create more competitions, build more and higher stage, let Bianlong show its vitality and charm.

\section{B. Strengthening the organization construction of the Bianlong}

In recent years, with the strong promotion of the General Administration of sports of the people's Republic of China, good results have been achieved in establishing fitness organizations around the masses [5]. There is a sense of belonging in an organization, and a sense of belonging has a driving force. Mass sports has a strong spontaneity, which is the voluntary participation of the general public for the purpose of fitness, entertainment, social and other purposes. The establishment of mass sports organizations can not only regulate the development of mass sports, but also stimulate the enthusiasm of participants and strengthen their sense of belonging. At present, led by the China whip and peg-top Federation, various large, medium and small whip, pegtop and Bianlong associations have been established all over the country. 


\section{Bianlong into the campus}

If a sport enters the campus, especially the classroom, it means that the sport has been recognized and supported by the society and the country, and it also means that the sport has turned from the original sports form to the standardized, scientific and popular way [6]. Students are the main force of the future, their ideology determines the future, their interests and hobbies also determine the future trend. For students, the Bianlong sport can not only achieve the purpose of physical exercise, but also play the educational function of spreading Chinese traditional culture. At present, in Changzhou, Jiangsu Province, Bianlong has entered some primary and secondary school classes and exercises, and achieved good development trend, which also provides a reference for the national Bianlong into the campus.

\section{CONCLUSION}

As a new national traditional sports, Bianlong has developed rapidly because it is conducive to people's fitness and rehabilitation needs, and meets the spiritual needs of people's leisure and entertainment. The development of Bianlong is still in its infancy, and the future development path is also unknown. As a sport with Chinese traditional cultural symbols, whiplash bears the mission of spreading Chinese traditional culture, and its development has a long way to go.

\section{References}

[1] Hu Xiaofei. Regular exercise acupoint BL 43 can be healthy [J]. School Physical Education in China,1997, (06): 51-52.

[2] Zhu Xianmin, Zhang Min,Wang Shiwei. The origin and application of the acupoint BL $43[\mathrm{~J}]$. Journal of traditional Chinese medicine literature, 2013, 31(04): 26-28.

[3] Zhang Dengfeng. Sports culture value of diabolo [J]. Sports Culture Guide, 2008, (11): 43-44+47.

[4] Liu Hongchun, Gao Minxu. The Origin, Development, Development Strategy and the Value of Diabolo [J]. Sports science and technology literature Bulletin, 2014, 22 (04): 115-116.

[5] Zhang Yanrong. On the historical evolution of Diabolo and Its Contemporary Development [J]. Sports Culture Guide, 2017, (06): 70-74.

[6] Zhang Baogen,Huang Xiaochun. Study on Modern Inheritance of Chinese Traditional Sports from the Angle of Cultural Changes [J] Journal of Guangzhou Institute of Physical Education,2009, 29(05): 44-48. DOI: 10.13830/j.cnki.cn44-1129/g8. 2009.05. 012. 